\title{
Gunite and Associated Tanks \\ Dry Well Conductivity \\ Monitoring Report, Oak Ridge National Laboratory, \\ Oak Ridge, Tennessee
}

\section{February 1998-December 1998}

Date Issued-April 1999

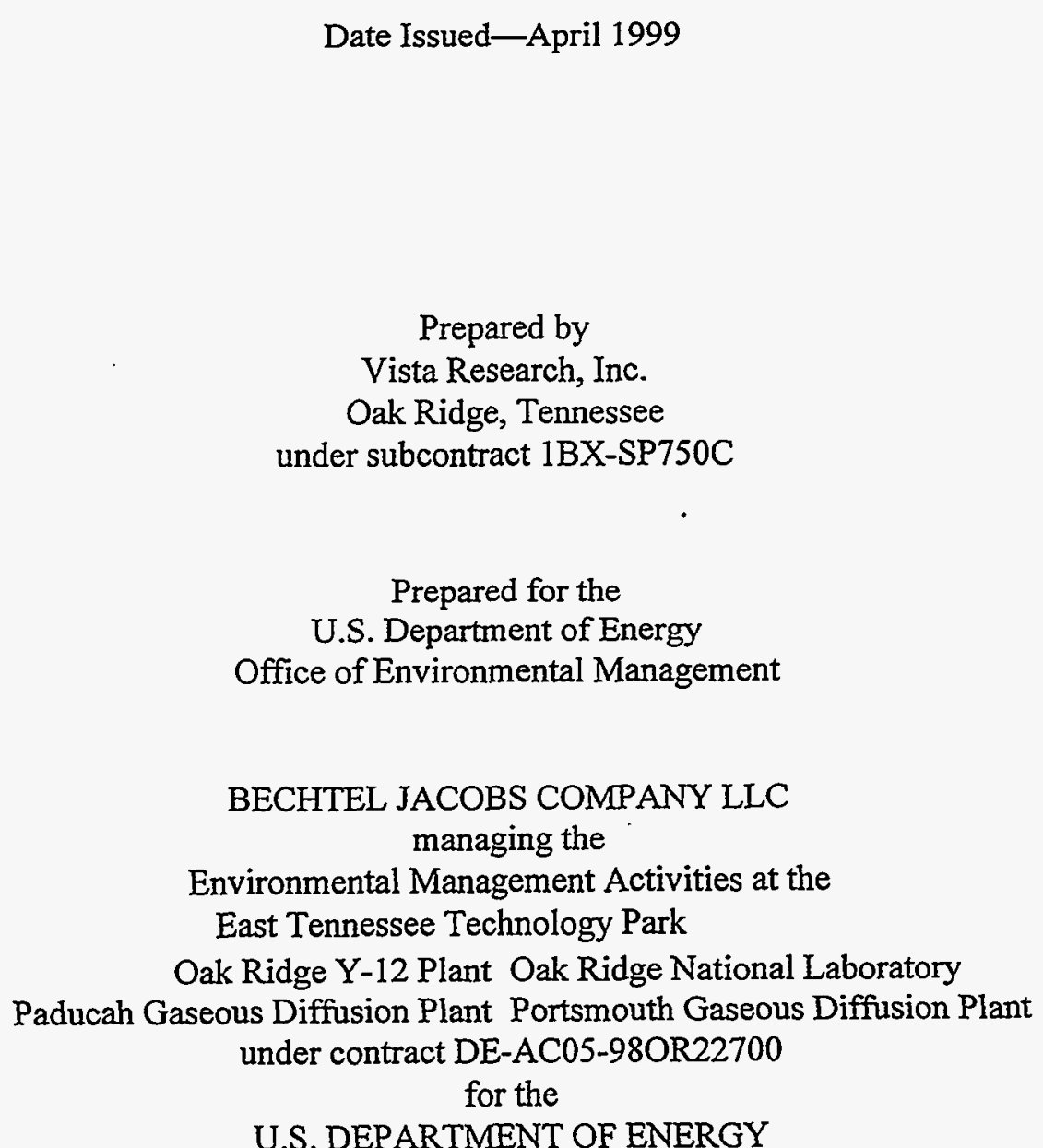

U.S. DEPARTMENT OF ENERGY 


\section{DISCLAIMER}

This report was prepared as an account of work sponsored by an agency of the United States Goverament. Neither the United States Government nor any agency thereof, nor any of their empioyees, makes any warranty, express or implied, or assumes any legal liability or responsibility for the accuracy, completeress, or usefulness of any information, apparatus, product, or process disclosed, or represents that its use would not infringe privately owned rights. Refereace berein to any specific commercial product, process, or service by trade name, traderaark, inanufac. turer, or otherwise does not necessarily constitute or imply its endorsement. recommendation, or favoring by the United States Government or any agency thereof. The views and opinions of authors expressed herein do not necessarily state or reflect those of the United States Government or any agency thereof. 


\section{DISCLAIMER}

Portions of this document may be illegible in electronic image products. Images are produced from the best available original document. 


\section{PREFACE}

This report, "Gunite and Associated Tanks Dry Well Conductivity Monitoring Report, Oak Ridge National Laboratory, Oak Ridge, Tennessee February 1998-December 1998” (BJC/OR-247), was developed under Work Breakdown Structure 6.1.01.41.05.05.05 (Activity Data Sheet 3301, "WAG 1"). This document provides the Environmental Restoration Program with the dry well conductivity monitoring data for the gunite tanks in the South Tank Farm for the period from February 1998 through December 1998. Information provided in this report forms part of the technical basis for criticality safety, systems safety, engineering design and waste management as they apply to the Gunite and Associated Tanks treatability study and waste removal actions. 


\section{CONTENTS}

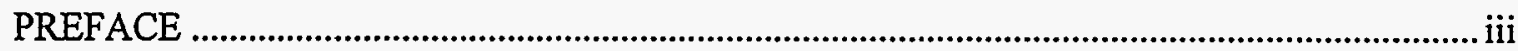

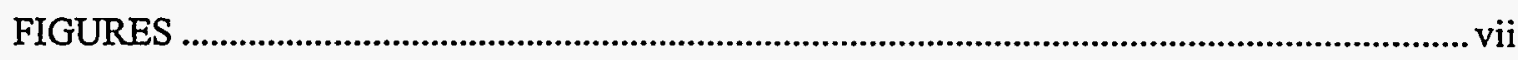

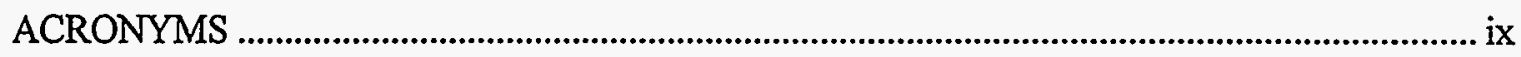

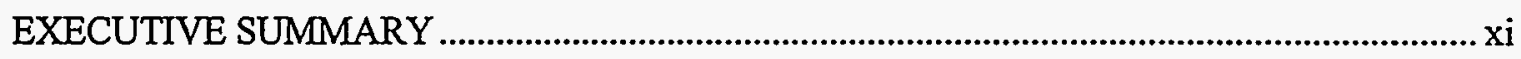

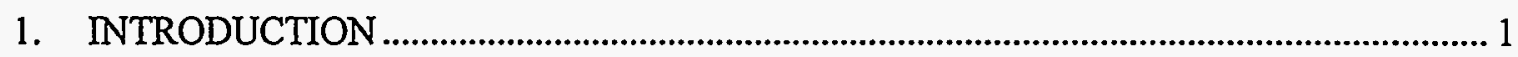

2. OVERVIEW OF MONITORING, SLUICING AND CONSTRUCTION

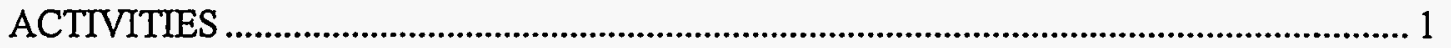

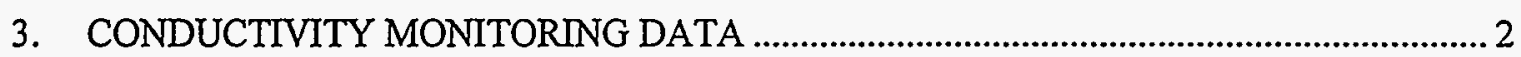

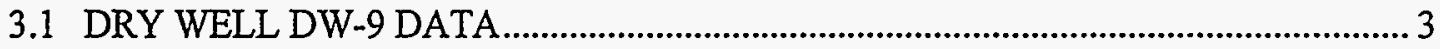

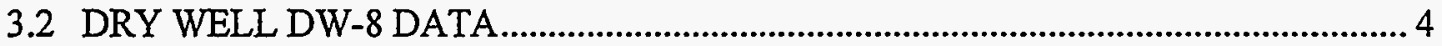

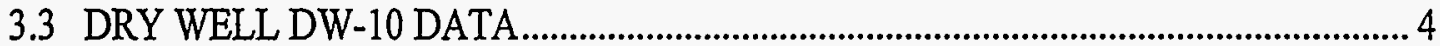

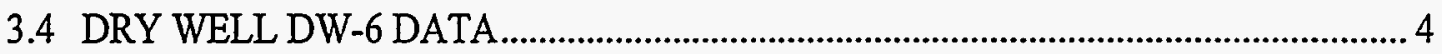

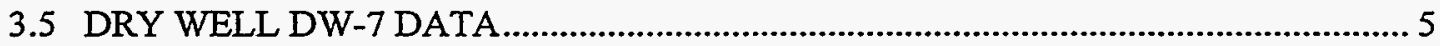

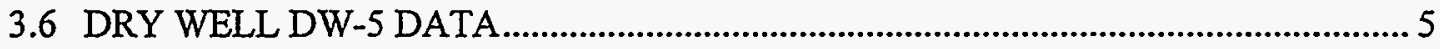

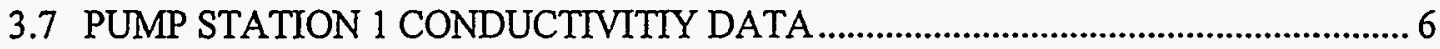

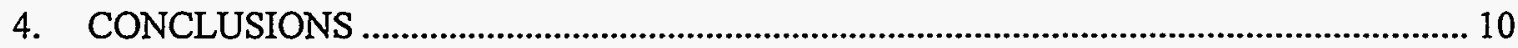

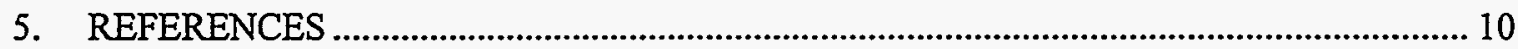




\section{FIGURES}

1. Plan view showing the location of the gunite tanks in the NTF and STF, the dry wells adjacent to each tank, and the drain system leading to PS1 ...................................................... 2

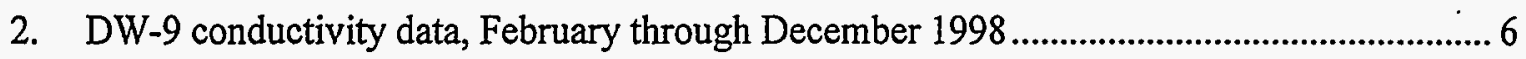

3. DW-8 conductivity data, February through December 1998 .................................................. 7

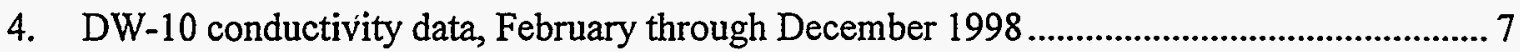

5. DW-6 conductivity data, March through December 1998 ..................................................... 8

6. DW-7 conductivity data, July through December 1998......................................................... 8

7. DW-5 conductivity data, September through December 1998 ............................................... 9

8. PS1 conductivity data, February through December 1998 ..................................................... 9 


\section{ACRONYMS}

$\begin{array}{ll}\text { CMM } & \text { Conductivity monitoring method } \\ \text { GAAT } & \text { Gunite and Associated Tanks } \\ \text { LLLW } & \text { Liquid low-level waste } \\ \text { NTF } & \text { North Tank Farm } \\ \text { PS1 } & \text { Pump Station 1 } \\ \text { SLR } & \text { Simulated liquid release } \\ \text { SOCC } & \text { Sluicing Operations Control Center } \\ \text { STF } & \text { South Tank Farm } \\ \text { WOCC } & \text { Waste Operations Control Center }\end{array}$





\section{EXECUTIVE SUMMARY}

A waste removal program is being implemented for the Gunite and Associated Tanks Operable Unit at Oak Ridge National Laboratory, Oak Ridge, Tennessee. The waste is being removed by means of remotely operated, in-tank, confined sluicing equipment. During sluicing operations the dry wells adjacent to each of the tanks are instrumented so that potential releases can be detected by means external to the tank. The method of detection is by monitoring the electrical conductivity of the water in the dry well associated with each tank (Lockheed Martin Energy Systems 1996, 1997a, 1997b, 1997c and 1998).

This report documents the dry well conductivity monitoring data for the period from February 1998 through December 1998. The dry wells monitored during this period include DW-5, DW-6, DW-7, DW-8, DW-9 and DW-10. The conductivity of the water passing through Pump Station 1 (PSI) was also monitored. During this period the sluicing activities at Tank W- 6 were initiated and successfully completed. In addition, flight mixers were used to remove wastes from Tank W-5, and sluicing operations were initiated on Tank W-7. Presented in this report are the dry well conductivity, rainfall, tank level, and other appropriate information relevant to the analysis and interpretation of the monitoring data for the reporting period.

A thorough analysis of the monitoring results from the six dry wells in the STF and PS1 for the period between February 1998 and December 1998 indicates that no releases have occurred from the gunite tanks being monitored. Overall, the dry well conductivity monitoring continues to provide a robust and sensitive method for detecting potential releases from the gunite tanks and for monitoring seasonal and constructionrelated changes in the dry well and drain system. 


\section{INTRODUCTION}

A waste removal program is being implemented for the Gunite and Associated Tanks (GAAT) Operable Unit at Oak Ridge National Laboratory, Oak Ridge, Tennessee. The waste is being removed by means of remotely operated, in-tank, confined sluicing equipment. The dry wells connected to the tanks in the South Tank Farm (STF) are instrumented to monitor these tanks externally, through the use of the conductivity monitoring method (CMM), so that potential releases during sluicing operations can be detected. A detailed description of the CMM is provided in earlier reports (Lockheed Martin Energy Systems 1996, 1997a, 1997b, 1997c and 1998).

This report documents CMM data collected during the period from February 1998 through December 1998. The dry wells monitored during this period include DW-5, DW-6, DW-7, DW-8, DW-9 and DW-10. The conductivity of the water passing through Pump Station 1 (PS1) was also monitored, since the water from the dry well and drain system in the STF flows through PS1.

The CMM is based on the fact that there is a significant difference in conductivity between the liquid in the tanks (which has high conductivity) and the water in the dry wells (which has low conductivity). Interpretation of the conductivity monitoring data requires an understanding not only of the response in the dry well to potential releases but also of the response to non-release-related factors. Previous studies have shown that even a relatively small release $(0.5 \mathrm{gal} / \mathrm{h})$ would result in a significant increasing trend in the conductivity of the water in the dry well (Lockheed Martin Energy Systems 1997a, 1997b and 1997c). Nonrelease-related factors such as rainfall, seasonal variations in groundwater quality, and construction activities can also cause increases in dry well conductivity. These factors are taken into account during the routine processing and analysis of the data in order to reduce the probability of false alarms while maintaining the sensitivity of the CMM.

An overview of the monitoring and sluicing activities is provided in Sect. 2. Section 3 presents the data and analysis of the dry well conductivity monitoring for the six tanks in the STF and PS1.

\section{OVERVIEW OF MONITORING, SLUICING AND CONSTRUCTION ACTIVITIES}

Sluicing operations were conducted on Tanks W-5, W-6 and W-7 during the reporting period. The construction of the in-tank sluicing platform at Tank W-6 was completed in February 1998; sluicing was started in April and completed in September. During late September and October, the sluicing platform and equipment were moved to Tank W-7; sluicing activities there were initiated in late October and are ongoing. Flight mixers were installed in Tank W-5 in October 1998 and sluicing of this tank was completed in early December. Tanks W-9 and W-8 were used to consolidate sluiced material and supernatant from Tanks W-5, W-6 and W-7. Tank W-9 was the primary tank for temporary consolidation of the sluiced material, and Tank W-8 was used to store the supernatant liquids. The W-8 and W-9 dry wells (DW-8 and DW-9) are connected in parallel to both the Waste Operations Control Center (WOCC) and the Sluicing Operations Control Center (SOCC) to provide for continuous, real-time monitoring during sluicing operations.

PS1 is the down-gradient collection point for all the water that flows through the STF dry well and drain system. As part of the overall monitoring for the STF, the conductivity of the water at PS1 was also 
monitored. Figure 1 shows the location of Tanks in both the North Tank Farm (NTF) and STF. Also shown in this figure are the dry wells adjacent to each tank and the drain system that carries the groundwater in the NTF and STF to PS1.

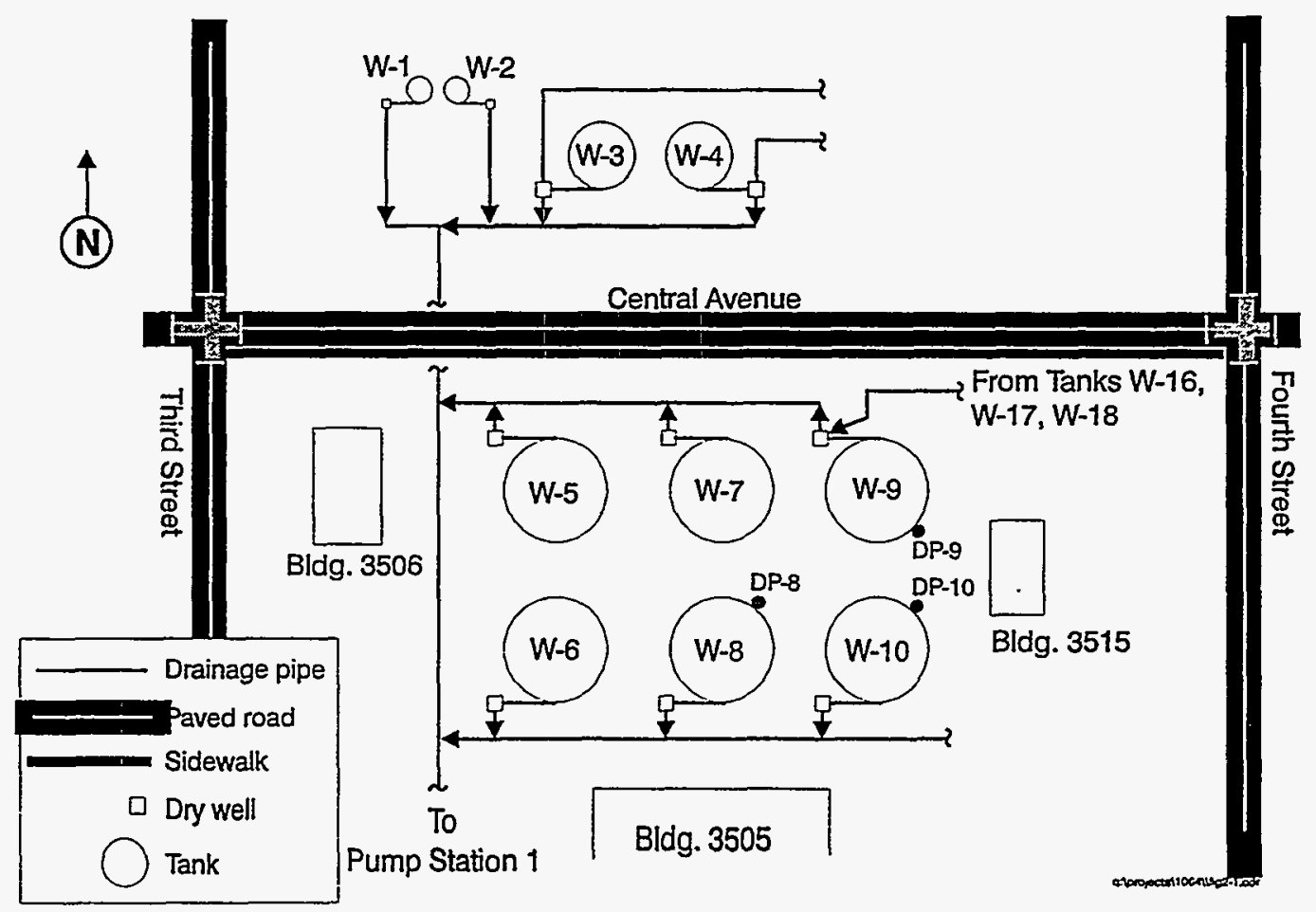

Fig. 1. Plan view showing the location of the gunite tanks in the NTF and STF, the dry wells adjacent to each tank, and the drain system leading to PS1.

Construction activities related to site preparation in the STF were completed during the early part of this reporting period. As discussed in the previous monitoring-report (LMES, 1998), the construction activities in some cases impacted the conductivity measurements. In particular, gravel backfilling and riser installation, when coincident with heavy rainfall, caused conductivity readings in the dry wells to rise significantly. These effects were still evident during February and March 1998 but were not a problem during the remainder of the reporting period. Construction-related impact on conductivity monitoring is discussed further in Sect. 3.

\section{CONDUCTIVITY MONITORING DATA}

Conductivity in the six STF dry wells was monitored during the reporting period. The data served several purposes: (1) to monitor Tank W-9 while it was being used for temporary consolidation of sluiced material from Tanks W-6, W-5 and W-7; (2) to monitor Tank W-8 while it was being used for temporary storage of supernatant liquids from Tank W-9; (3) to monitor Tanks W-6, W-5 and W-7 during sluicing operations and to monitor Tank W-10 in preparation for sluicing operations in 1999. DW-8 and DW-9 were connected to the WOCC and the SOCC for continuous real-time monitoring and recording of data during 
the entire reporting period. DW-6 was connected to the WOCC and the SOCC during Tank W-6 sluicing operations from March through September. DW-7 was connected to the WOCC and the SOCC in October, in preparation for sluicing operations in Tank W-7. DW-5 and DW-10 were connected to data loggers as were DW-6 and DW-7 when not connected to the WOCC.

Time series plots of conductivity data from DW-9, DW-8, DW-6, DW-7, DW-5 and DW-10 are presented in Figs. 2 through 7 respectively. The conductivity plot for PS1 is presented in Fig. 8. So that they may be more easily compared, all the figures are presented at the end of Sect. 3, arranged in the order in which the data are discussed. The plots in Figs. 2, 3, 4, and 8 cover the period from February through December 1998. The plots in Figs. 5, 6 and 7 are for shorter time periods depending on when the conductivity instrumentation was installed in the dry wells. All of the plots show the conductivity data as well as the cumulative rainfall (in inches) and the level of tank liquid (in feet). The scale for the conductivity data $(0$ to $2000 \mu \mathrm{S} / \mathrm{cm})$ is shown on the left axis of each plot. On the right axis there is a dual-purpose scale in increments of 0 through 50. For cumulative rainfall this represents a range of 0 to 50 in. For tank level it represents liquid level in feet above the bottom of the tank. Also shown on the plots is the maximum tank liquid level (approximately $12 \mathrm{ft}$ ). Superimposing the three sets of data allows a comparison of the conductivity levels, rainfall and significant changes in the level of liquid in the tank. Lastly, the plots are annotated, as appropriate, to show sluicing activities during the reporting period.

The cumulative rainfall plots are calculated for the period from 1 February 1998 through the end of December 1998. The tank level data reflect the listed liquid transfers into and out of W-8 and W-9 and show the liquid levels in Tanks W-6, W-5 and W-7 during sluicing activities. The data for the six STF dry wells and PS1 are discussed below.

\subsection{DRY WELL DW-9 DATA}

The conductivity data for DW-9 are presented in Fig. 2, which includes the cumulative rainfall data and the Tank W-9 level data for the period from February through December 1998. DW-9 conductivity generally ranged between 600 and $800 \mu \mathrm{S} / \mathrm{cm}$. There are some small gaps in data due to problems associated with transmitting the signals to the WOCC. In particular there is a data gap in February and also one in late October through early November. During these periods, the conductivity was monitored closely on the instrument readout at the tank. The spikes and somewhat abrupt changes in conductivity data shown on the plot are the result of instrument drift and re-calibration activities. In particular, a sharp increase in conductivity is seen the June data. This is correlated with a period of significant rainfall. The conductivity sensor was checked and re-calibrated. The sharp decrease in July was also a calibration problem that was corrected.

The liquid level data in Fig. 2 clearly show the liquid transfers into and out of Tank W-9 during the reporting period. Between late October and early November 1998 there is a gap in the data due to problems in the connection between the STF and the WOCC. The levels in Tank W-9 were, however, monitored locally at the STF during this period. Despite the minor data gaps and instrumentation problems, the conductivity and level data for DW-9 and W-9 show the liquid integrity of Tank W-9 to be intact, with no releases indicated during the reporting period. 


\subsection{DRY WELL DW-8 DATA}

The conductivity data for DW-8 are presented in Fig. 3, which includes the cumulative rainfall data and the Tank W-8 level data for the period from February through December 1998. DW-8 conductivity generally ranged between 600 and $800 \mu \mathrm{S} / \mathrm{cm}$. The slow increase and subsequent decrease in conductivity during the period February through May are a residual effect of construction activities at the STF. The increase was caused by the emplacement of stabilized limestone base material, which, with the infiltration of rainfall, caused the conductivity of the groundwater in DW-8 to increase. The construction-related effects are discussed in detail in the previous conductivity monitoring report (Lockheed Martin Energy Systems, 1998). As projected in the previous report, the conductivity increase caused by the construction activities corrected itself over time, as shown on the DW-8 conductivity plot. The data for DW-8 are smoother than for DW-9 and do not have some of the gaps seen in the DW-9 data. The main reason is that there were no significant tank construction, equipment or instrumentation activities at W-8. At W-9 there were a lot of activities because of its use as the primary holding tank for sluiced material from W-6, W-5 and W-7.

The liquid level data in Fig. 3 reflect the liquid transfers into and out of Tank W-8 during the reporting period. The changes in liquid level in Tank W-8 are not correlated with the changes in DW-8 conductivity or with the rainfall data shown in Fig. 3. The conductivity and level data show the liquid integrity of W-8 to be intact, with no releases indicated during the reporting period.

\subsection{DRY WELL DW-10 DATA}

The conductivity data for DW-10 are presented in Fig. 4, which includes the cumulative rainfall data and the Tank W-10 level data for the period from February through December 1998. DW-10 conductivity generally ranged between 400 and $600 \mu \mathrm{S} / \mathrm{cm}$. Residual effects from the construction activities (emplacement of limestone stabilized base) in the STF can be seen in the February and March data. The spikes in the data are correlated with rainfall fall events (seen as step increases in the cumulative rainfall plot). As predicted (Lockheed Martin Energy Systems, 1998), these effects diminished with time. Some of the small abrupt changes in conductivity seen in Fig. 4 are the result of instrument checks and re-calibration.

The liquid level data in Fig. 4 remained basically constant during the reporting period. A careful examination of the plot will show some small upward changes in the liquid level that are correlated with significant rainfall events. This is consistent with previous level data from Tank W-10 that showed small increases in liquid level due to rainfall infiltration through the tank dome during significant rainfall events. The conductivity and level data show the liquid integrity of W-10 to be intact, with no releases indicated during the reporting period.

\subsection{DRY WELL DW-6 DATA}

The conductivity data for DW-6 are presented in Fig. 5, which includes the cumulative rainfall data and the Tank W-6 level data for the period from March through December 1998. Also shown is the time frame for the W-6 in-tank sluicing operations. DW- 6 conductivity generally ranged between 600 and $700 \mu \mathrm{S} / \mathrm{cm}$ during and after the sluicing operations. The conductivity-measuring instrumentation was installed at DW- 6 in early March, but there were a series of electrical interference problems that resulted in the jagged data shown on the plot. These problems were corrected and subsequently there were no significant problems encountered during the actual sluicing operations at Tank W-6. Some of the increasing trends in DW- 6 
conductivity shown on the plot appear to be correlated with rainfall events, and some are just calibration adjustments.

The Tank W-6 liquid level data shown in Fig. 5 remained relatively constant during the sluicing operations. Around mid-August the in-tank level instrumentation was disconnected in preparation for the wall-cleaning operations in the tank. After completion of the W-6 sluicing operations, a very small residual amount of process water was left in the bottom of the tank. Tank levels were monitored manually for the remainder of the reporting period. Tank W-6 water level data are currently monitored online at the WOCC. The conductivity and level data show the liquid integrity of W-6 to be intact, with no releases indicated during the reporting period.

\subsection{DRY WELL DW-7 DATA}

The conductivity data for DW-7 are presented in Fig. 6, which includes the cumulative rainfall data and the Tank W-7 level data for the period from July through December 1998. The conductivity instrumentation was installed in DW-7 in early July, and conductivity generally ranged between 600 and $800 \mu \mathrm{S} / \mathrm{cm}$ during the reporting period. The data show several sharp increases in conductivity that appear to be correlated with rainfall. The instrumentation was also checked and re-calibrated several times. There is a gap in the data from the middle of September until the beginning of October. This data gap occurred when DW-7 was disconnected from the logger in preparation for connecting it directly to the WOCC and the sluicing platform. During this period, the conductivity was monitored manually at the readout for the dry well conductivity instrument. No unusual changes in conductivity were observed during this period. The DW-7 conductivity was and is being monitored continuously at the WOCC during the ongoing W-7 sluicing operations.

The Tank W-7 liquid level data are shown at the bottom of Fig. 6 . The level increase in early August was the result of the addition of approximately 30,000 gal of liquid to the tank. The liquid was added to reduce the radiation hazard to workers that were constructing the sluicing platform over Tank W-7. Historically, Tank W-7 has had a very low liquid level. Therefore, the dry well conductivity and level data were monitored very closely during and after the liquid addition to make sure that there were no unexpected releases from the tank. No problems were encountered, and sluicing construction operations were able to proceed. The conductivity and level data show the liquid integrity of W-7 to be intact, with no releases indicated during the reporting period.

\subsection{DRY WELL DW-5 DATA}

The conductivity data for DW-5 are presented in Fig. 7, which includes the cumulative rainfall data and the Tank W-5 level data for the period from September through December 1998. The conductivity instrumentation was installed in DW-5 in early September, and conductivity generally ranged between 800 and $1000 \mu \mathrm{S} / \mathrm{cm}$ during the reporting period. The DW-5 conductivity has been consistently higher than at the other STF dry wells. The higher conductivity readings are the result of the stabilized limestone base used in the STF (Lockheed Martin Energy Systems, 1998). The limestone base caused the average conductivity in all of the dry wells to go up by several hundred $\mu \mathrm{S} / \mathrm{cm}$. The effect is just more pronounced at DW-5. Because of the elevated readings, close attention was paid to DW-5 during sluicing operations. The DW-5 conductivity shows several in-creases in September that are correlated with rainfall events that followed a long dry spell. The conductivity sensor was also re-calibrated in October and found to be reading high. 
The Tank W-5 level data shown in Fig. 7 are based on manual level readings during liquid transfers. To provide liquid for the flight mixer operations, liquid (supernate) was transferred into W-5 from W-8. The resulting supernate and suspended sludge were then periodically transferred to tank W-9. The fluctuations seen in Fig. 7 represent the transfers in and out of W-5. The conductivity data show the liquid integrity of $\mathrm{W}-5$ to be intact, with no releases indicated during the reporting period.

\subsection{PUMP STATION 1 CONDUCTIVTTY DATA}

The conductivity data for PS1 are presented in Fig. 8, along with the cumulative rainfall data for the period from February through December 1998. The conductivity at PS1 generally ranged between 400 and $500 \mu \mathrm{S} / \mathrm{cm}$ during the reporting period. There is a spike in the data in early February that is related to a rainfall event and the construction activities in the STF (Lockheed Martin Energy Systems, 1998). There appears to be an overall decreasing trend in the data during the reporting period. This may reflect diminishing effects from the STF construction activities (emplacement of stabilized limestone base). Overall, the PS1 conductivity data show no indication of liquid releases from the STF tanks during the reporting period.

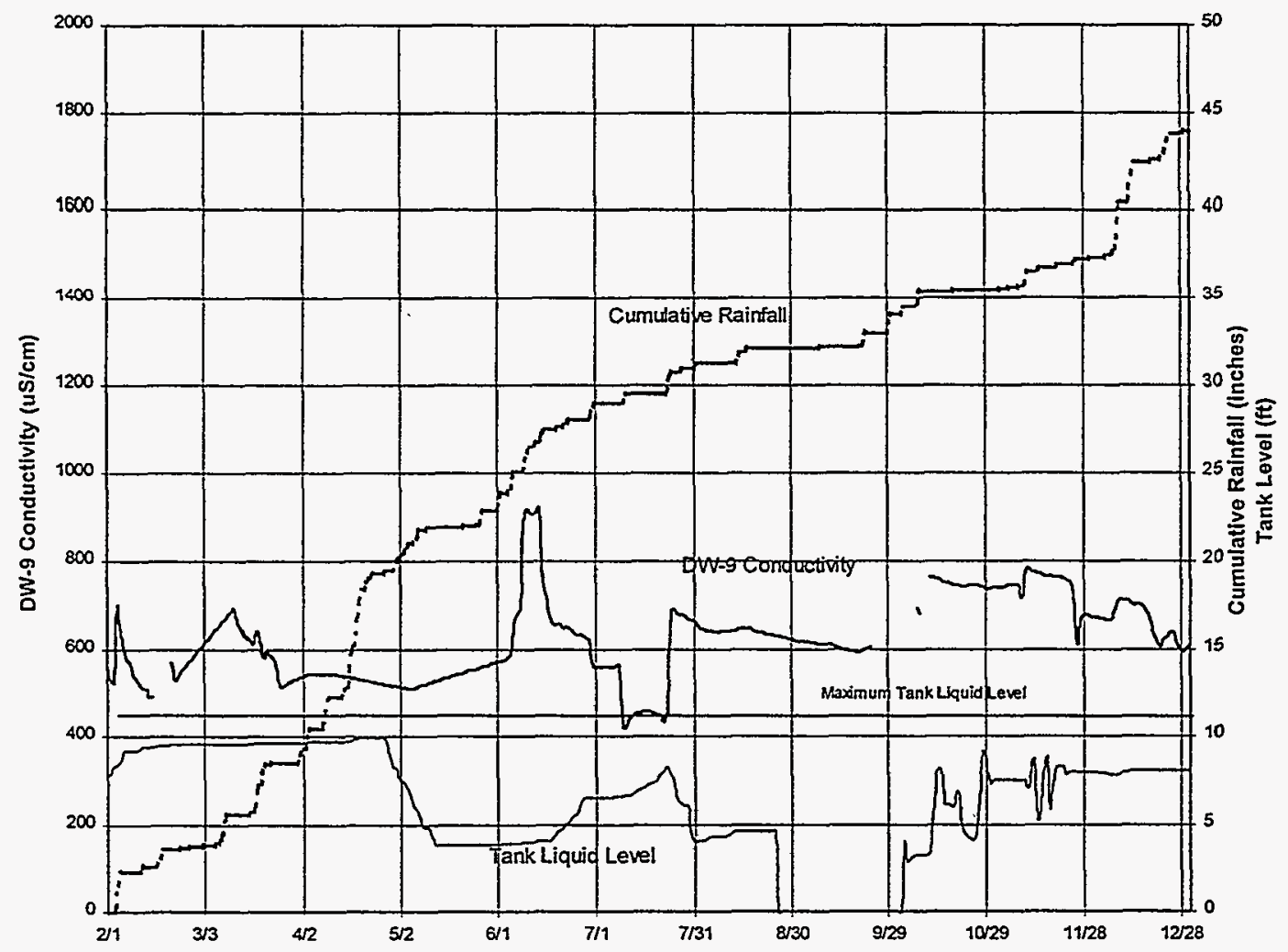

Fig. 2. DW-9 conductivity data, February through December 1998. 


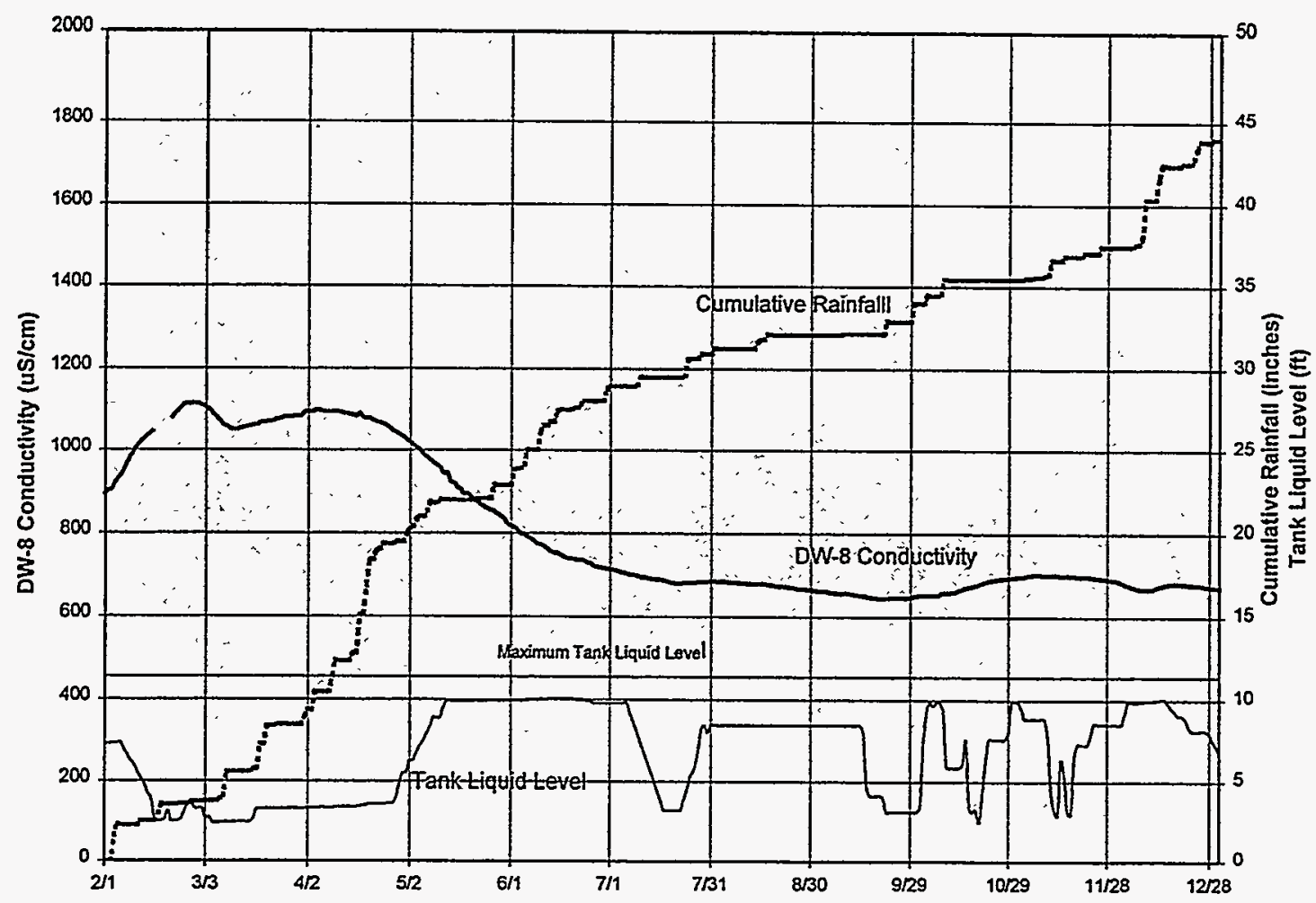

Fig. 3. DW-8 conductivity data, February through December 1998.

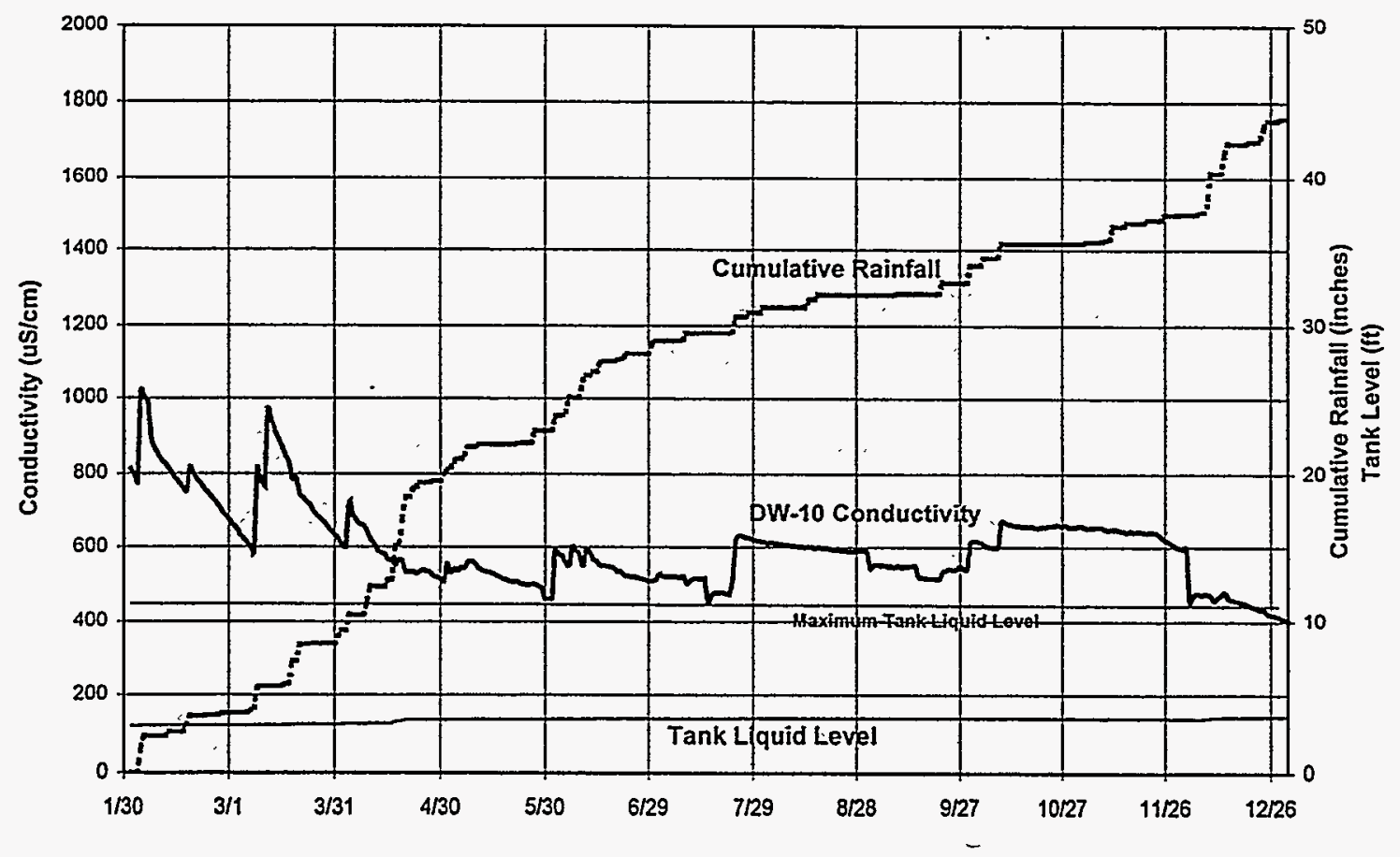

Fig. 4. DW-10 conductivity data, February through December 1998. 


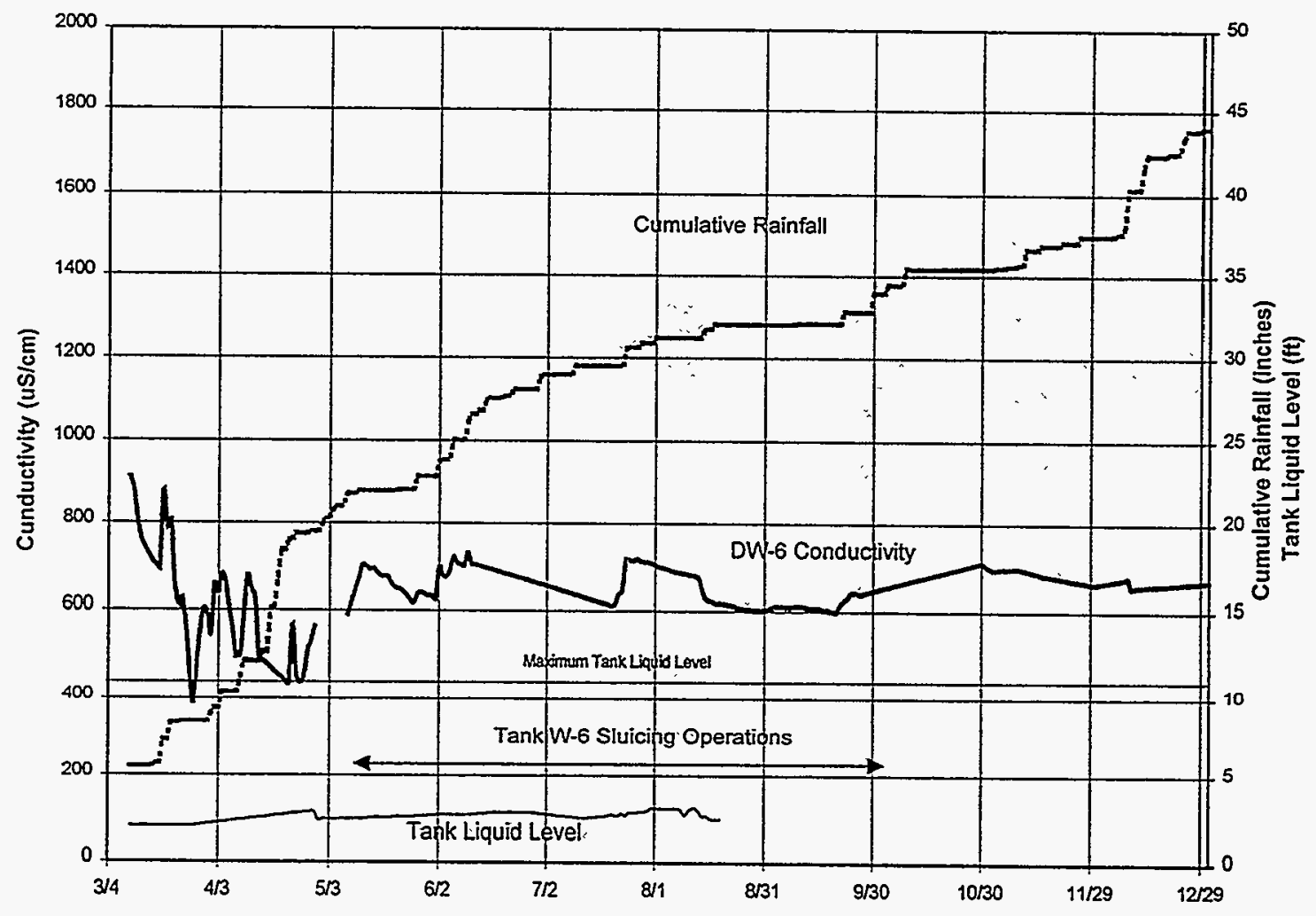

Fig. 5. DW-6 conductivity data, March through December 1998.

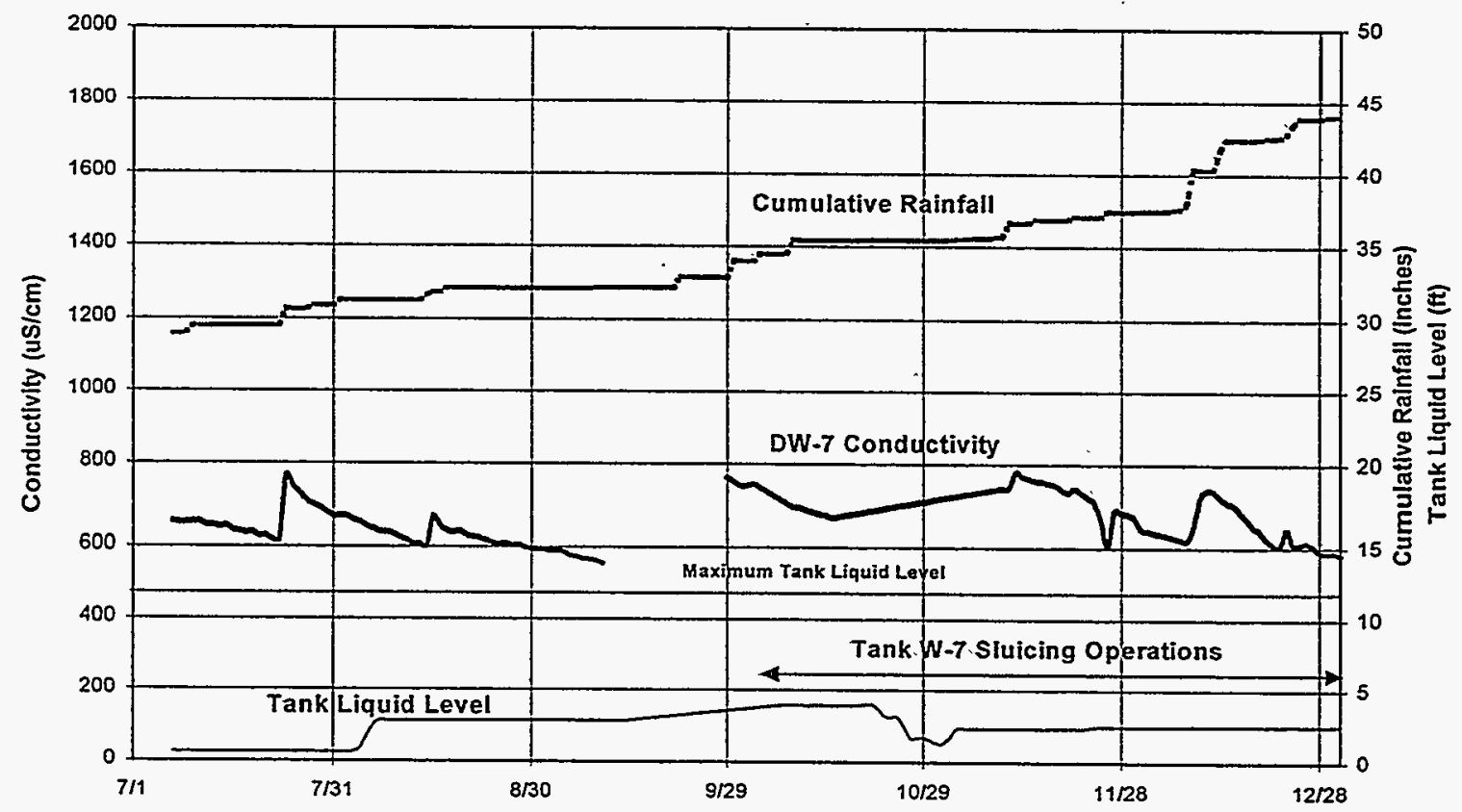

Fig. 6. DW-7 conductivity data, July through December 1998. 

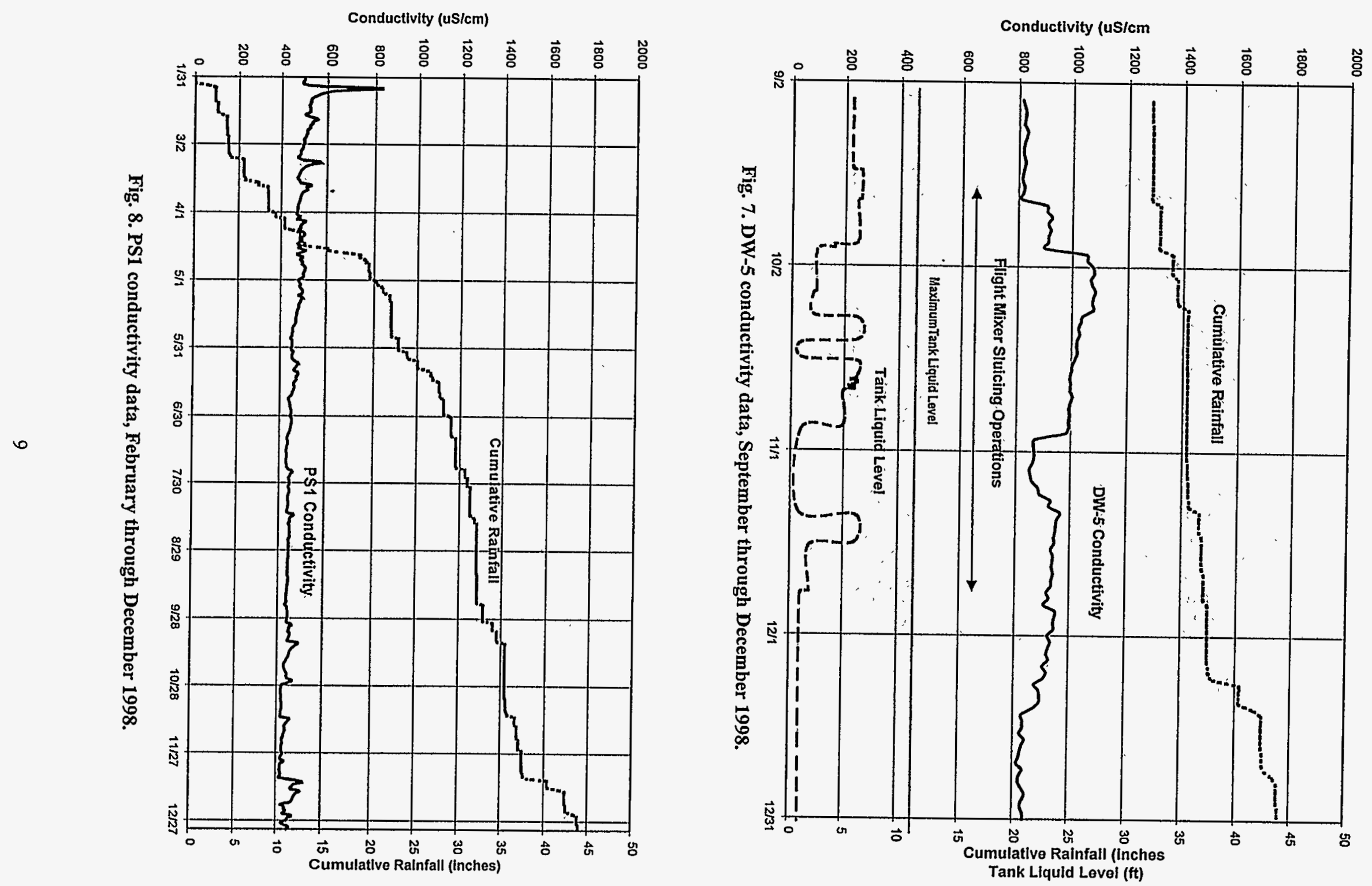


\section{CONCLUSIONS}

A thorough analysis of the monitoring results from the six dry wells in the STF and PSI for the period between February 1998 and December 1998 indicates that no releases have occurred from the gunite tanks being monitored. Overall, the dry well conductivity monitoring continues to provide a robust and sensitive method for detecting potential releases from the gunite tanks and for monitoring seasonal and constructionrelated changes in the dry well and drain system.

\section{REFERENCES}

Lockheed Martin Energy Systems, Inc., 1998. "GAAT Dry Well Conductivity Monitoring Report, July 1997 Through January 1998, Oak Ridge National Laboratory, Oak Ridge, Tennessee.” ORNL/ER-437, Lockheed Martin Energy Systems, Inc., Oak Ridge, Tenn.

Lockheed Martin Energy Systems, Inc., 1997a. "Evaluation and Monitoring Plan for Consolidation Tanks: Gunite and Associated Tanks Operable Unit, Waste Area Grouping 1, Oak Ridge National Laboratory, Oak Ridge, Tennessee.” ORNL/ER-396, Lockheed Martin Energy Systems, Inc., Oak Ridge, Tenn.

Lockheed Martin Energy Systems, Inc., 1997b. "Baseline Monitoring and Simulated Liquid Release Test Report for Tank W-9, Oak Ridge National Laboratory, Oak Ridge, Tennessee." ORNL/ER-410, Lockheed Martin Energy Systems, Inc., Oak Ridge, Tenn.

Lockheed Martin Energy Systems, Inc., 1997c. "Dry Well Conductivity Monitoring Report for Tanks W-8, W-9 and W-10, Oak Ridge National Laboratory, Oak Ridge, Tennessee." ORNL/ER-421, Lockheed Martin Energy Systems, Inc., Oak Ridge, Tenn.

Lockheed Martin Energy Systems, Inc., 1996. "Preliminary Evaluation of Liquid Integrity Monitoring Methods for Gunite and Associated Tanks at the Oak Ridge National Laboratory." ORNL/ER-349, Lockheed Martin Energy Systems, Inc., Oak Ridge, Tenn.

Vista Research, Inc., 1996. "Simulated Liquid Release Demonstrations on Gunite Tanks W-3 and W-4 in the North Tank Farm." Vista Research Report 1060-TR-96-001, Vista Research, Inc., Oak Ridge, Tenn.

Martin Marietta Energy Systems, 1992. "Site Characterization Summary Report for Waste Area Grouping 1 at Oak Ridge National Laboratory, Oak Ridge, Tennessee." ORNL/ER-131/V1-4/D2, Martin Marietta Energy Systems, Inc., Oak Ridge, Tenn. 


\section{RECORD COPY DISTRIBUTION}

File-EMEF DMC-RC 